\title{
Do Empathy and Psychological Mindedness Affect Police Officers' Decision to Enter Crisis Intervention Team Training?
}

\author{
Michael T. Compton, M.D., M.P.H., Beth Broussard, M.P.H., C.H.E.S., Dana Hankerson- \\ Dyson, M.P.H., C.H.E.S., Shaily Krishan, M.P.H., and Tarianna Stewart-Hutto, M.S. \\ At the time of the study, all authors were affiliated with the Department of Psychiatry and \\ Behavioral Sciences, Emory University School of Medicine, Atlanta, Georgia. Dr. Compton and \\ Ms. Broussard are now with the Department of Psychiatry and Behavioral Sciences, George \\ Washington University School of Medicine and Health Sciences, 2150 Pennsylvania Ave., N.W., \\ Washington, D.C. 20037 (mcompton@mfa.gwu.edu).
}

\section{Abstract \\ Objective-It is generally assumed that police officers' self-selection into the specialized, week- long Crisis Intervention Team (CIT) training is a critical feature of the overarching CIT program. However, issues pertaining to self-selection have not been empirically examined. In this study, it was hypothesized that officers entering CIT training, especially those self-selecting into it, would have: (1) a higher likelihood of exposure to/experience with mental health issues and mental health professionals, and (2) greater empathy and psychological mindedness.}

\begin{abstract}
Methods-177 officers-including 109 non-CIT officers, 24 pre-CIT officers assigned to training, and 44 pre-CIT officers who voluntarily self-selected into training-were assessed before and after their week-long classes (non-CIT officers were enrolled in other courses). Basic sociodemographic characteristics were assessed, and four psychometrically sound measures of empathy and psychological mindedness were administered. Associations between officer status and sociodemographic variables, past exposure/experience, and empathy and psychological mindedness were examined.
\end{abstract}

Results-The three groups did not differ on three of four exposure/experience variables; however, self-selected pre-CIT officers were more likely to have prior exposure to mental health professionals. No differences were found between the three groups on measures of empathy or psychological mindedness. One measure of empathy increased significantly after the week-long CIT training.

Conclusions-Findings did not support the hypothesis that officers self-selecting into CIT training would have greater baseline empathy and psychological mindedness. While there may be other justifiable reasons to argue for the importance of volunteering, these two traits do not appear to be greater among officers self-selecting into CIT.

\section{Keywords}

Crisis Intervention Team; Empathy; Law Enforcement; Police; Psychological mindedness

\section{INTRODUCTION}

Recognizing the detrimental schism between expectations placed on law enforcement officers and the minimal training they typically receive pertaining to psychiatric crisis 
situations, the Crisis Intervention Team (CIT) program was developed in Memphis, Tennessee in 1988 (1). CIT has since been recognized as an exemplary collaboration between local mental health professionals, police officers, and advocacy groups (2-4). This program provides officers with 40 hours of specialized training consisting of classroom lectures, visits to local mental health services, and performance-based exercises allowing for mastery of de-escalation techniques (5). However, it is increasingly noted that the CIT model is "more than just training" (2), meaning that other aspects of the CIT model-in addition to the curriculum - must be in place for communities to benefit from embracing the model. As stated in the Core Elements published by national leaders of CIT, the model comprises Ongoing, Operational, and Sustaining Core Elements that are essential to the program's success (6). There are estimated to be over 1,200 CIT programs currently in operation in cities and counties across the United States (Dupont, R., personal communication, October 18, 2010).

It has been assumed that self-selection of officers into CIT training is a crucial aspect of the program. As stated in the Operational Core Elements pertaining to the CIT officer (6), "officers within a patrol division should voluntarily apply for CIT positions" (p. 12). A number of authors cite self-selection as a key feature of their local programs (2,7-9), and some have proposed the presence of a desired "selection bias," meaning that officers' attributes predispose them to seeking - and subsequently effectively incorporating into their fieldwork-CIT training (10-12). That is, officers who self-select into CIT may be characterologically different from, and better suited than, those who do not, though no previous research has examined this assumption. Furthermore, it has been previously noted that CIT officers are more likely to report a family history of psychiatric treatment or knowing someone in the mental health profession compared to non-CIT officers $(12,13)$, which may represent another aspect of the desired "selection bias" for officers opting into the training.

This study was conducted to provide the first empirical examination of several potential "behind-the-scenes" characteristics involved in self-selection of officers into CIT training. Two key characteristics of interest were empathy and psychological mindedness. Psychological mindedness can be understood as an individual's capability and interest to be in touch with and reflect on one's range of psychological states (14). One's aptitude for psychological mindedness tends to be a fairly stable personality characteristic $(14,15)$. In relation to CIT training, officers' ability to empathize, and their awareness of their own psychological state, should make for a successful CIT officer. Additionally, in a recent qualitative study, officers suggested that empathy is a character trait needed for successful work as a CIT officer (16). The primary hypotheses of this study were that officers entering CIT training — particularly those self-selecting into the training — would have a higher likelihood of past exposure to/experience with mental health issues and greater empathy and psychological mindedness. A secondary hypothesis was that the four measures of empathy and psychological mindedness represent stable traits (as opposed to changing after CIT training). These hypotheses were tested using data provided by 177 police officers, 109 of whom were non-CIT officers and 68 of whom were officers entering CIT training (24 having been assigned and 44 having voluntarily self-selected into training).

\section{METHODS}

Data were collected from a sample of police officers attending non-CIT and CIT classes from various counties throughout the state of XXXX. The non-CIT officers attended training classes covering topics such as sexual assault, domestic violence, and supervision at the XXXX Public Safety Training Center. The officers in the CIT trainings were recruited from six municipalities. The assessment was administered twice, on Monday mornings (initial 
assessment) and Friday afternoons (post-training assessment). The university's institutional review board approved the informed consent forms signed by all participants. The overall self-administered, anonymous survey, embedded with the measures described below, required approximately one hour to complete.

A detailed, self-administered demographics form-assessing important covariates (e.g., age, gender, years having served as a police officer) as well as a number of other basic sociodemographic variables — was completed by participants at the beginning of the survey. The question, "Are you a Crisis Intervention Team (CIT) officer?" was included to assess the CIT status of officers in the non-CIT trainings, and 16 CIT officers identified in that way were previously excluded from analyses (resulting in the 109 non-CIT officers reported on herein). For officers currently in CIT training, participants were asked how they entered the training ("Volunteered/Self-selected" or "Was assigned/Told to do it"). Four variables, used in prior survey-based research with police officers $(10,12,13)$, assessed the officers' personal history of exposure to/experience with mental health issues. Specifically, officers were asked: "Have any of your family members ever received or are they currently receiving treatment for a mental health problem (such as therapy, counseling, or medicine for mental or emotional problems)?" "Have you known someone within your circle of friends who has been or is currently undergoing treatment for a mental health problem?" "Have you ever received or are you currently receiving treatment for a mental health problem?" and "Have you or any members of your family or any of your friends been active as either a professional or volunteer helper in the field of counseling, therapy, psychiatry, psychology, or social work?"

Empathy was measured using two instruments. First, the Empathy Quotient (EQ) was initially developed as a 60-item measure in which responses are given on a 4-point Likert scale ranging from "strongly agree" to "strongly disagree" (17). To minimize participant burden, 28 items previously examined in a principal components analysis-which derived cognitive empathy, emotional reactivity, and social skills factors (17)—were included in the present study. A total score from among these 28 items was computed, ranging 0-56, with higher scores representing more empathic responses. EQ total scores showed good internal consistency in the present sample, with a Cronbach's $a$ of .88 at the initial assessment ( $a=$. 87 among non-CIT officers and $a=.89$ among CIT officers). As noted below, an exploratory analysis also examined cognitive empathy, emotional reactivity, and social skills domains, which include items such as "I can tell if someone is masking their true emotion," "I tend to get emotionally involved in a friend's problems," and "I don't tend to find social situations confusing," respectively.

Second, the Empathic Concern subscale of the Interpersonal Reactivity Index (IRI-EC) was used to further assess empathy (other IRI subscales not used in the present study include fantasy, perspective-taking, and personal distress) (18). Responses to the seven self-report items of the IRI-EC are given on a 5-point Likert scale ranging from "does not describe me well" to "describes me very well." Constructs measured include experiences of feeling warmth, compassion, and concern for others enduring negative experiences. Total scores range $0-28$, with higher score indicating a greater tendency to experience feelings of warmth and concern for others. Sample items include: "I would describe myself as a pretty softhearted person" and "Other people's misfortunes do not usually disturb me a great deal," the latter being reverse-scored. The instrument has acceptable test-retest reliability (18). The IRI-EC showed moderate internal consistency in the present sample, with a Cronbach's a coefficient of .62 at the initial assessment ( $a=.57$ among non-CIT officers and $a=.66$ among CIT officers), though it should be noted that the subscale has only seven items, and $a$ is influenced by the number of items. 
Psychological mindedness was also assessed using two measures. First, the Balanced Index of Psychological Mindedness (BIPM) is a self-report measure consisting of 14 items scored on a 5-point Likert scale, with response options ranging from "not true," to "very much true." Sample items include: "I am often not aware of my feelings" (which is reverse-scored) and "I am better off when being in touch with my feelings." A higher total BIPM score reflects more interest, greater insight, and higher psychological mindedness (14). Internal consistency has been demonstrated in adult community samples and in psychiatric samples (14), and in the current sample the Cronbach's $a$ was .71 at the initial assessment ( $a=69$ among non-CIT officers and $a=.71$ among CIT officers).

The second measure of psychological mindedness, the Psychological Mindedness Scale (PMS), measures one's ability to see relations among thoughts, feelings, and actions, with the goal of learning the meanings and causes of experiences and behavior (19). The PMS is a self-report measure including 45 items scored on a 4-point scale, with response options ranging from "strongly disagree" to "strongly agree." Sample items include: "Usually, if I feel an emotion, I can identify it," and "I am always curious about the reasons people behave as they do." Twenty items are reverse scored, and the total PMS score (ranging 45-180) is the sum of individual item responses, with higher scores indicating greater psychological mindedness. The instrument has good internal consistency in psychiatric (19) and nonclinical samples (20); in the present study the Cronbach's a was .88 at the initial assessment ( $a=.86$ among non-CIT officers and $a=.89$ among CIT officers).

Basic sociodemographic characteristics of the three groups of officers (also referred to as "officer status;" non-CIT officers, pre-CIT officers assigned to the training, and pre-CIT officers who had voluntarily self-selected into training) were compared. Inter-correlations among the psychological variables of interest were examined using Pearson productmoment correlation coefficients. Associations between officer status and past exposure/ experience, empathy, and psychological mindedness were examined using chi-square tests of independence and analyses of variance (ANOVAs). As necessary, these tests were followed by logistic regression models and analyses of covariance (ANCOVAs) to control for the effects of potential confounding variables. The secondary hypothesis, pertaining to stability of empathy and psychological mindedness, relied on paired-samples $t$-tests. All analyses were conducted using the SPSS 16.0 software package, and all hypothesis tests were two-tailed with a significance criterion of $p<.05$.

\section{RESULTS}

The three groups of officers did not differ with respect to age or years of education (Table 1). Officers assigned to CIT training had served as a police officer for fewer years than the non-CIT officers $(F=5.40 ; d f=2,171 ; p=.005)$. The three groups did not differ with respect to gender or ethnicity, though when excluding the "other" race category (due to small sample sizes), non-CIT officers were more likely to be white/Caucasian and less likely to be black/African American compared to assigned pre-CIT officers $\left(\chi^{2}=6.36, d f=2, p=.04\right)$. Furthermore, as shown in Table 1, there were statistically significant differences in relationship status $\left(\chi^{2}=12.04, d f=4\right.$, Fisher's exact $\left.p=.01\right)$ and total income $\left(\chi^{2}=13.27, d f=4\right.$, $p=.01)$ across the three groups.

The IRI-EC score was only modestly correlated with BIPM and PMS scores ( $r=.29$ and $r=$. 28 , respectively), and moderately correlated with EQ scores ( $r=.43)$. The EQ score was also moderately correlated with the BIPM score ( $r=.44)$. The strongest correlations were between the PMS score and EQ and BIPM scores ( $r=.62$ and $r=.57$, respectively). Because high correlations (e.g., $r>$.70) were not observed, subsequent analyses proceeded considering 
each of the four empathy and psychological mindedness variables as non-redundant, somewhat separate constructs.

Given that officers in the three groups differed with respect to years having served as a police officer, race, relationship status, and total household income, associations between these four sociodemographic variables and the four empathy and psychological mindedness variables were examined. Whereas race, relationship status, and total household income were not significantly associated with any of the four psychological characteristics, years having served as a police officer was modestly but significantly $(p<.05)$ inversely correlated with IRI-EC ( $r=-.17)$, BIPM ( $r=-.21)$, and PMS ( $r=-.16)$ scores.

The three groups did not differ with respect to three of the four exposure/experience variables (Table 2). However, self-selected pre-CIT officers were more likely to respond affirmatively to the question, "Have you or any members of your family or any of your friends been active as either a professional or volunteer helper in the field of counseling, therapy, psychiatry, psychology, or social work?" Specifically, $41 \%$ of self-selected pre-CIT officers reported this type of exposure to mental health professionals, compared to only $17 \%$ and $21 \%$ of assigned pre-CIT officers and non-CIT officers, respectively. This association was obscured (no longer significant) when the two groups of pre-CIT officers were combined and compared to non-CIT officers.

Exposure to mental health professionals was unrelated to years having served as a police officer, relationship status, and total household income, ensuring that the association was not confounded by these variables. However, race (dichotomized as either white/Caucasian or black/African American) was significantly associated with exposure to mental health professionals ( $60 \%$ of white/Caucasian officers compared to $40 \%$ of black/African American officers; $\left.\chi^{2}=4.19, d f=1, p=.04\right)$. Thus, to examine the association of officer status and exposure to mental health professionals while controlling for the effects of race, a binary logistic regression model was conducted (recoding the three-level officer status variable into two dummy variables). Model results are shown in Table 3. Black/African American race (relative to white/Caucasian race), being a non-CIT officer, and being assigned to CIT training (relative to self-selecting/volunteering into CIT training) were independently associated with a lower odds of reporting exposure to mental health professionals.

Although self-selected pre-CIT officers had higher scores numerically on all four measures of empathy and psychological mindedness, none of these modest differences were statistically significant. The cognitive empathy, emotional reactivity, and social skills subscales of the EQ also did not differ. The results did not change when the two groups of pre-CIT officers were combined and compared to non-CIT officers. Because years having served as a police officer was significantly inversely correlated with IRI-EC, BIPM, and PMS scores as noted above, ANCOVAs were used to re-assess differences in mean scores across the three groups while controlling for the effects of this covariate (to exclude any possible negative confounding). In all three instances, when removing the effect of years having served as a police officer, the three groups of officers did not differ on empathy or psychological mindedness.

Analyses were then conducted to test the secondary hypothesis that the four measures of empathy and psychological mindedness represent stable traits (as opposed to changing after CIT training). Data were available from both the initial assessment and post-training assessment in 65 officers participating in CIT training (two officers who had been assigned to the training did not participate in the post-assessment and one officer who had volunteered did not participate in the post-assessment; thus, differences in demographic variables among those included and not included in the follow-up assessment could not be 
evaluated). As shown in Table 4, one measure of empathy (IRI-EC) and both measures of psychological mindedness (BIPM and PMS) did not change after the week-long CIT training course. However, the other measure of empathy (EQ) significantly increased after the training (25.2 \pm 8.4 to $28.0 \pm 8.3$; paired $t=-5.07, d f=44, p^{<.001)}$. Of note, these findings did not change when data from 22 assigned pre-CIT officers and 36 self-selected CIT officers were examined separately. In an exploratory analysis, the three subscales of the EQ were then examined; the cognitive empathy and emotional reactivity subscale scores differed $(p<.001)$, though the difference in the social skills subscale scores did not reach statistical significance $(p=.07)$.

Data were available from both the initial assessment and post-training assessment in 59 nonCIT officers. Given that post-training data could not be collected from 50 non-CIT participants, we examined potential differences between those who did and did not provide follow-up data. The two groups did not differ with respect to age, years of educational attainment, years having served as a police officer, race, gender, ethnicity, marital status, and income. However, officers who did not complete the post-training assessment were more likely to endorse having a family member who had ever received or are currently receiving mental health treatment $\left(50 \%\right.$ compared to $\left.26 \% ; \chi^{2}=6.71 ; d f=1, p=.010\right)$ and were more likely to report having known someone within their circle of friends who has been or is currently in mental health treatment $\left(52 \%\right.$ compared to $\left.31 \% ; \chi^{2}=4.89 ; d f=1, p=.03\right)$. However, non-CIT officers from whom post-training data could not be collected did not differ on the four variables of interest (pertaining to empathy and psychological mindedness) relative to those who completed the post-assessment. Regarding the 59 non-CIT officers with available data at both assessments, scores on all four measures remained stable from

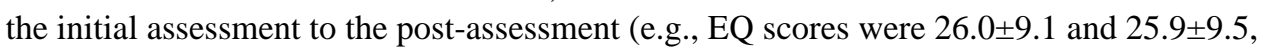
respectively).

\section{DISCUSSION}

Several demographic characteristics differed across the three groups of officers, which likely reflects variation in CIT implementation across police departments involved in the study (e.g., differences in uptake of CIT in municipalities that differ in salaries) rather than representing broadly generalizable differences between CIT and non-CIT officers. Differences in salaries may also be related to differences in years of service.

Sociodemographic variables should be assessed in future studies of CIT and non-CIT officers given that such variables may represent important covariates. Regarding the primary hypotheses, self-selected pre-CIT officers were roughly twice as likely to report a history of exposure to mental health professionals, which remained true even after controlling for a potential confounder, race. However, quite contrary to the a priori expectations, the three groups did not differ with respect to empathy or psychological mindedness. In terms of the secondary hypothesis, three psychological variables remained stable before and after CIT training (suggesting that they are, in fact, traits), though one measure of empathy did change after CIT training. There may be two reasonable explanations for why scores on that particular empathy measure improved after CIT training. First, several items of the EQ could pertain to some of the active listening and verbal de-escalation skills that officers receive during their CIT training; for example: "I am good at predicting how someone will feel," "I can sense if I am intruding, even if the other person doesn't tell me," and "I can easily work out what another person might want to talk about." Second, the EQ scale has greater variability due to a larger range of scores, which may have allowed changes to be more easily detectable (though differences in the other measures were negligible).

Although many CIT officers in the current sample reported volunteering into the training program, others had been assigned to it by their respective department, which deviates from 
the recommendation that officers should ideally volunteer (6). This, in conjunction with the lack of differences in empathy and psychological mindedness among the three officer groups at baseline, raise questions about the assumption that CIT-volunteering officers are inherently more suited for the program. In fact, the lack of differences in these key characterologic attributes may support some police departments' practices to train all officers, or to assign officers to CIT training based on the departments' needs and preferences. However, the lack of distinction between the three groups of officers in empathy and psychological mindedness does not necessarily negate the merit of the argument that CIT-volunteering officers are in some way more appropriate for the program. In fact, the significant difference in exposure to mental health professionals by group could indicate that volunteering officers are more in tune with CIT's tenet of "responsibility and accountability to consumers of mental health services, their relatives, and the community (2)." Considering that officers' characteristics are thought to be important determinants of effective CIT implementation (21), these findings may also justify a closer scrutiny of individual departments' requirements and selection procedures for enrollment into CIT training. Officers who self-selected into CIT training were more likely to have reported exposure to mental health professionals, which may be an influential factor in these officers' decision to volunteer into, and perhaps level of appropriateness for, CIT training.

Several methodological limitations should be recognized. First, a number of police departments were represented, and sample sizes from the individual departments were too small to allow sub-analyses. Second, among the diverse characterologic variables that could have been examined, only two, which were deemed to be most salient (given that officers' interactions with individuals with mental illnesses would obviously benefit from empathy and psychological mindedness), were assessed. Before firm conclusions can be drawn in this arena, further research should examine other characteristics of officers, perhaps including conscientiousness and altruism. Third, given that self-selected pre-CIT officers did have numerically higher scores on the four measures of empathy and psychological mindedness, and in light of the fact that sample sizes in the three groups were modest $(n=109,24$, and 44), it could be argued that a much larger sample size may reveal significant effects.

However, given the modest magnitude of these effects (the largest effect was between assigned and self-selected pre-CIT officers on the PMS, with a Cohen's $d$ of .45 , representing a small to medium effect, though most effects were much smaller), such differences between groups are unlikely to be practically meaningful in routine interactions between officers and individuals with mental illnesses who are in crisis. Also, measurement limitations could play a role in the findings. Perhaps the empathy most relevant to CIT officers is context- or target-specific, and a measure of empathy related to persons with mental illnesses would be more appropriate to discern differences between groups. Lastly, some classes attended by non-CIT officers focused on topics of domestic violence or sexual assault, which may attract officers similar to CIT officers in terms of empathy. However, these classes were not mental health-related and a number of participants were recruited from a class focused on supervision.

\section{CONCLUSIONS}

While there may be other justifiable reasons to argue for the importance of volunteering, characterologic empathy and psychological mindedness do not appear to be greater among officers self-selecting into CIT. Importantly, empathy (measured with the EQ) significantly improved after CIT training, and to our knowledge, this is the first demonstration of changes in empathy during CIT training, though the magnitude of the effect was small. As research on the very widely disseminated CIT model continues to advance, a greater understanding of the factors that attract certain police officers into the training, and the practices of various police departments in selecting officers, is warranted. 


\section{Acknowledgments}

This study was supported by a grant from the National Institute of Mental Health (R01 MH082813) to the first author. The authors greatly appreciate the support and assistance provided by Ms. XXXX, Ms. XXXX, and Ms. XXXX in the study implementation and collection of data.

\section{References}

1. Steadman H, Deane M, Borum R, et al. Comparing outcomes of major models of police responses to mental health emergencies. Psychiatric Services. 2000; 51:645-649. [PubMed: 10783184]

2. Cochran S, Deane MW, Borum R. Improving police response to mentally ill people. Psychiatric Services. 2000; 51:1315-1316. [PubMed: 11013336]

3. Dupont R, Cochran S. Police response to mental health emergencies - barriers to change. Journal of the American Academy of Psychiatry and the Law. 2000; 28:338-344. [PubMed: 11055533]

4. Oliva, JR.; Haynes, N.; Covington, DW., et al. Crisis Intervention Team (CIT) programs, in Responding to Individuals with Mental Illnesses. Compton, MT.; Kotwicki, RJ., editors. Jones and Bartlett Publishers, Inc.; Sudbury, MA: 2007.

5. Oliva JR, Compton MT. A statewide Crisis Intervention Team (CIT) initiative: evolution of the Georgia CIT program. Journal of the American Academy of Psychiatry and Law. 2008; 36:38-46.

6. Dupont, R.; Cochran, S.; Pillsbury, S. Crisis Intervention Team Core Elements. The University of Memphis School of Urban Affairs and Public Policy, Department of Criminology and Criminal Justice, CIT Center; Memphis, TN: 2007. from the World Wide Web: http://cit.memphis.edu/ CoreElements.pdf [Retrieved January 4th, 2010]

7. Bower DL, Pettit G. The Albuquerque police department's crisis intervention team: a report card. FBI Law Enforcement Bulletin. 2001; 70:1-6.

8. Munetz MR, Morrison A, Krake J, et al. Statewide implementation of the Crisis Intervention Team program: the Ohio model. Psychiatric Services. 2006; 57:1569-1571. [PubMed: 17085603]

9. Skeem J, Bibeau L. How does violence potential relate to Crisis Intervention Team responses to emergencies? Psychiatric Services. 2008; 59:201-204. [PubMed: 18245166]

10. Compton MT, Esterberg ML, McGee R, et al. Crisis intervention team training: changes in knowledge, attitudes, and stigma related to schizophrenia. Psychiatric Services. 2006; 57:11991202. [PubMed: 16870973]

11. Compton MT, Chien VH. Factors related to knowledge retention after Crisis Intervention Team (CIT) training for police officers. Psychiatric Services. 2008; 59:1049-1051. [PubMed: 18757600]

12. Compton MT, Demir Neubert BN, Broussard B, et al. Use of force preferences and perceived effectiveness of actions among Crisis Intervention Team (CIT) police officers and non-CIT officers in an escalating psychiatric crisis involving a subject with schizophrenia. Schizophrenia Bulletin. (in press).

13. Bahora M, Hanafi S, Chien VH, et al. Preliminary evidence of effects of Crisis Intervention Team training on self-efficacy and social distance. Administration and Policy in Mental Health and Mental Health Services Research. 2008; 35:159-167. [PubMed: 18040771]

14. Nyklicek I, Denollet J. Development and evaluation of the Balanced Index of Psychological Mindedness (BIPM). Psychological Assessment. 2009; 21:32-44. [PubMed: 19290764]

15. McCallum, M.; Piper, W. Basic characteristics of psychological mindedness and related concepts. In: McCallum, M.; Piper, W., editors. Psychological Mindedness: A Contemporary Understanding. Lawrence Erlbaurn Associates, Inc., Publishers; New Jersey: 1997. p. 246-255.

16. McGriff J, Broussard B, Demir-Neubert D, et al. Implementing a Crisis Intervention Team (CIT) police presence in a large international airport setting. Journal of Police Crisis Negotiations. 2010; 10:153-165.

17. Lawrence EJ, Shaw P, Baker D, et al. Measuring empathy: reliability and validity of the Empathy Quotient. Psychological Medicine. 2004; 34:911-924. [PubMed: 15500311]

18. Davis MH. A multidimensional approach to individual differences in empathy. JSAS Catalog of Selected Documents in Psychology. 1980; 10:85. 
19. Conte HR, Plutchik R, Jung BB, et al. Psychological mindedness as a predictor of psychotherapy outcome: a preliminary report. Comprehensive Psychiatry. 1990; 31:426-431. [PubMed: 2225801]

20. Shill MA, Lumley MA. The psychological mindedness scale: factor structure, convergent validity and gender in a non-psychiatric sample. Psychology and Psychotherapy: Theory, Research and Practice. 2002; 75:131-150.

21. Watson AC, Morabito MS, Draine J, et al. Improving police response to persons with mental illness: a multi-level conceptualization of CIT. International Journal of Law and Psychiatry. 2000; 31:359-368. [PubMed: 18632154] 
Table 1

Sociodemographic Characteristics of the Three Subgroups of Police Officers

\begin{tabular}{|c|c|c|c|c|c|c|}
\hline & $\begin{array}{l}\text { Non-CIT Officers } \\
(n=109)\end{array}$ & $\%$ & $\begin{array}{l}\text { Assigned Pre-CIT } \\
\text { Officers }(n=24)\end{array}$ & $\%$ & $\begin{array}{l}\text { Self-Selected Pre-CIT } \\
\text { Officers }(n=44)\end{array}$ & $\%$ \\
\hline Age, years & $38.5 \pm 7.1$ & & $38.6 \pm 9.7$ & & $38.7 \pm 8.9$ & \\
\hline Educational attainment, years & $13.7 \pm 1.7$ & & $13.9 \pm 1.6$ & & $14.2 \pm 1.8$ & \\
\hline Years having served as a police officer $*$ & $12.2 \pm 6.8$ & & $7.3 \pm 6.7$ & & $10.2 \pm 6.9$ & \\
\hline Gender, male & 91 & 84 & 18 & 75 & 35 & 80 \\
\hline Ethnicity, non-Hispanic & 106 & 97 & 21 & 91 & 42 & 98 \\
\hline \multicolumn{7}{|l|}{ Race $^{*}$} \\
\hline white/Caucasian & 83 & 76 & 14 & 58 & 29 & 66 \\
\hline black/African American & 20 & 18 & 10 & 42 & 14 & 32 \\
\hline Other & 6 & 6 & 0 & 0 & 1 & 2 \\
\hline \multicolumn{7}{|l|}{ Relationship status * } \\
\hline Single and never married & 6 & 6 & 4 & 17 & 11 & 25 \\
\hline Married or living with a partner & 78 & 72 & 15 & 63 & 27 & 61 \\
\hline Separated or divorced & 25 & 23 & 5 & 21 & 6 & 14 \\
\hline \multicolumn{7}{|l|}{ Total income for everyone in the household ${ }^{*}$} \\
\hline$<\$ 40,000$ & 21 & 19 & 10 & 42 & 4 & 9 \\
\hline$\$ 40,001-\$ 60,000$ & 19 & 17 & 4 & 17 & 14 & 32 \\
\hline$>\$ 60,000$ & 69 & 63 & 10 & 42 & 26 & 59 \\
\hline
\end{tabular}

Statistically significant difference across groups, $p<.05$. 
Table 2

Bivariate Tests of Association between Officer Status and Personal and Family History of Psychiatric Treatment, Empathy, and Psychological Mindedness

\begin{tabular}{|c|c|c|c|c|c|c|}
\hline & $\begin{array}{l}\text { Non-CIT } \\
\text { Officers } \\
(n=109)\end{array}$ & $\%$ & $\begin{array}{l}\text { Assigned } \\
\text { Pre-CIT Officers } \\
(\mathbf{n = 2 4})\end{array}$ & $\%$ & $\begin{array}{l}\text { Self-Selected } \\
\text { Pre-CIT Officers } \\
(n=44)\end{array}$ & $\%$ \\
\hline \multicolumn{7}{|l|}{ Exposure/Experience Variables } \\
\hline Family history of receiving treatment & 40 & 37 & 6 & 25 & 14 & 32 \\
\hline History of receiving treatment among friends & 44 & 41 & 11 & 46 & 18 & 44 \\
\hline Personal history of receiving treatment & 10 & 9 & 2 & 8 & 2 & 5 \\
\hline Exposure to mental health professionals $*$ & 23 & 21 & 4 & 17 & 18 & 41 \\
\hline \multicolumn{7}{|l|}{ Empathy/Psychological Mindedness Variables } \\
\hline Empathic Concern (IRI-EC) & $18.5 \pm 3.5$ & & $18.7 \pm 3.9$ & & $19.6 \pm 3.9$ & \\
\hline Empathy Quotient (EQ) & $25.7 \pm 8.0$ & & $24.1 \pm 9.2$ & & $27.4 \pm 9.6$ & \\
\hline Balanced Index of Psychological Mindedness (BIPM) & $18.8 \pm 3.4$ & & $18.5 \pm 4.1$ & & $19.3 \pm 3.5$ & \\
\hline Psychological Mindedness Scale (PMS) & $132.1 \pm 11.8$ & & $127.9 \pm 10.0$ & & $134.0 \pm 14.8$ & \\
\hline
\end{tabular}

Statistically significant difference across groups, $p<.05$. 


\section{Table 3}

Logistic Regression Model Examining Independent Effects of Officer Characteristics and Race on Likelihood of Reporting Past Exposure to Mental Health Professionals

\begin{tabular}{|l|c|c|c|c|}
\hline & B & SE & OR & 95\% CI \\
\hline Race, black/African American $^{a}$ & -.81 & .41 & .45 & $.20-.99$ \\
\hline Officer status, non-CIT $^{b}$ & -1.06 & .41 & .34 & $.15-.76$ \\
\hline Officer status, assigned pre-CIT $^{b}$ & -1.40 & .64 & .25 & $.07-.87$ \\
\hline
\end{tabular}

${ }^{a}$ reference group $=$ Race, white/Caucasian

$b_{\text {reference group }}=$ Officer status, self-selected/volunteering CIT officers 
Table 4

Changes in Scores of Empathy and Psychological Mindedness after CIT Training ( $n=58$ )

\begin{tabular}{|l|l|l|l|l|l|}
\hline & Pre-CIT Training & Post-CIT Training & $\mathbf{t}$ & $\mathbf{d f}$ & $\mathbf{p}$ \\
\hline Empathic Concern (IRI-EC) & $19.1 \pm 3.8$ & $19.2 \pm 4.7$ & -.04 & 57 & .97 \\
\hline Empathy Quotient (EQ) & $25.2 \pm 8.4$ & $28.0 \pm 8.3$ & -5.07 & 44 & $<.001$ \\
\hline $\begin{array}{l}\text { Balanced Index of Psychological } \\
\text { Mindedness (BIPM) }\end{array}$ & $19.3 \pm 3.7$ & $19.4 \pm 4.1$ & -.34 & 57 & .74 \\
\hline $\begin{array}{l}\text { Psychological Mindedness Scale } \\
\text { (PMS) }\end{array}$ & $133.2 \pm 13.1$ & $134.3 \pm 13.8$ & -.98 & 47 & .33 \\
\hline
\end{tabular}

